\title{
Editorial: Loneliness Past and Present, and Its Effects on our Lives
}

\author{
Ami Rokach ${ }^{1,2,3, * \S}$ \\ ${ }^{l}$ York University, Canada \\ ${ }^{2}$ Walden University, USA \\ ${ }^{3}$ Center for Academic Studies, Israel
}

\section{INTRODUCTION TO SPECIAL ISSUE: LONELINESS AND ITS MANIFESTATIONS IN EVERYDAY LIFE}

Loneliness is present in all our lives. Continuously or intermittently, we all experience its searing pain, social alienation, and negative effects on our self-esteem. Loneliness carries a social stigma, and this special issue is dedicated to helping remove that stigma, by openly discussing, examining, and revealing how loneliness is intertwined in our lives, experienced, and coped with.

In this special issue we included eleven articles that explore the various manifestations of loneliness, and which were divided into four conceptual sections:

\section{LONELINESS IN EVERYDAY LIFE}

Snell [1] reviews the history of loneliness, since he maintains that despite the well-established research on this topic in psychology, sociology, and across a range of modern welfare disciplines, and despite the modern public, political and media concern about an 'epidemic' or 'time bomb' of loneliness, historians have been slow to explore the historical aspects of the problem. Snell undertakes to do it, and examines loneliness in literature, philosophy, psychology, in light of societal changes, and cultural dictates.

Rokach \& Philibert-Lignieres [2] wrote about what we see so frequently in every day: marital relationships that start with great love, intimacy and a positive outlook, and end with heart wrenching disappointment, damage to one's selfesteem, and infidelity, which often once discovered brings an end to the marriage.

Victims suffer. That is a given. Part of students' suffering includes loneliness and peer victimization. Pavri, [3] in her literature review, observed that while lonely students who have few friends and receive limited peer support are vulnerable to being victimized by their peers, loneliness also emerges as a salient outcome of persistent and chronic peer victimization. The article concludes with a review of schoolbased intervention approaches to alleviate bullying in children and youth.

*Address correspondence to this author at the York University, Canada, Walden University, USA; E-mail: arokach@yorku.ca

$\S$ Guest editor
Rokach \& Sha'ked [4] review the research that relates loneliness to illness and death, two conditions that we all will undergo at some point in our life. These two universal experiences are replete with loneliness, a sense of isolation, and a deep yearning not only for health and life, but for a meaningful connection with loved ones and carers.

\section{ASSESSING LONELINESS}

In their study, Junttila, Kainulainen \& Saari [5] compared subjective feelings of loneliness which were assessed by the following: frequency of loneliness over the last year, number of good friends, satisfaction with existing social relationships, and the short version of the UCLA Loneliness Scale. They studied the gender and age-related differences between lonely and non-lonely adults and as predictors for the self-reported consequences of loneliness. Consequently, they highlighted the importance of identifying loneliness in the prevention of psychosocial and economic issues, substance abuse and eating disorders, and the negative consequences that loneliness may have on health.

Victor et al. [6] asserted that we broadly know that loneliness as one ages is a dynamic experience with people becoming more or less lonely or staying the same over time. Consequently, in their paper they reported on one element of a small mixed method pilot study to investigate seasonal variations in loneliness over the course of one year and to test the effectiveness of tools used to collect data at repeated short intervals. Their research indicated that loneliness is dynamic even over shorter periods of time with participants reporting to be lonelier in the evenings, weekends and spring-summer period.

\section{LONELINESS, DISABILITY AND ILLNESS}

Segrin, Badger and Pasvogel [7] examined the associations between loneliness, emotional support, physical health, and psychological distress in Latinas with breast cancer and their supportive partners. Their study demonstrated that loneliness and emotional support were predictive of psychological distress and physical symptoms, in their sample. Additionally, emotional support minimized the association between physical symptoms and psychological distress. 
Pettite et al. [8] highlighted the connection between loneliness and physical health. Their review examined the link between loneliness and common chronic conditions including: heart disease, hypertension, stroke, lung disease, and metabolic disorders. They concluded that loneliness is a significant biopsychosocial stressor that is apparent in adults with hypertension, stroke, heart and/or lung disease. The relationships among loneliness, obesity, and metabolic disorders are understudied but current research indicates that loneliness is associated with obesity and with psychological stress in obese persons.

\section{ADDRESSING LONELINESS}

As a consequence of the proliferation of societal attempts to help the lonely, telephone help lines are now spread throughout the world. Campbell [9] provided a comprehensive review of the telephone help lines dedicated to helping the youth, and the reasons that children and adolescents do not take full advantage of that readily available extended hand.

Rosenstreich and Margalit [10] attended to the loneliness experienced by first year college and university students, loneliness and other related emotions that may hamper their academic achievements. Their study examined whether mindfulness practice may moderate the relations between perceived loneliness and academic performance, and whether mindfulness workshops could enhance performance memory. Their research suggested that loneliness was negatively correlated with recognition memory performance and with grades; that grades were higher in the mindfulness group than in the control group; and lastly, that mindfulness and loneliness interacted, such that loneliness negatively predicted academic grades only for students who did not practice mindfulness.
My thanks to the authors who shared with the readers and me their views, expertise, and research, and the reviewers whose contribution is very greatly appreciated. Reviewers included: David Teplin, Milada Disman, Martin Resnick, Eyal Rosenstreich, Chris Segrin, Christina Victor, Laurie Theeke, Kenneth Snell, and Ami Rokach.

I hope that you will find this special issue helpful, enlightening, and interesting.

\section{REFERENCES}

[1] Snell KDM. Agendas for the historical study of loneliness and lone living. Open Psychol J 2015; 8: 61-70.

[2] Rokach A, Philibert-Lignières G. Intimacy, loneliness and infidelity. Open Psychol J 2015; 8: 71-7.

[3] Pavri S. Loneliness: the cause or consequence of peer victimization in children and youth. Open Psychol J 2015; 8: 78-84.

[4] Rokach A, Sha'ked A. Ill health, death and loneliness: Mankind's companions. Open Psychol J 2015; 8: 85-8.

[5] Junttila N, Kainulainen S, Saari J. Mapping the lonely landscape assessing loneliness and its consequences. Open Psychol J 2015; 8 : 89-96.

[6] Victor C, Sullivan MP, Woodbridge R, Thomas M. Dancing with loneliness in later life: a pilot study mapping seasonal variations. Open Psychol J 2015; 8: 97-104.

[7] Segrin C, Badger T, Pasvogel A. Loneliness and emotional support predict physical and psychological distress in latinas with breast cancer and their supportive partners. Open Psychol J 2015;8: 105-12.

[8] Pettite T, Mallow J, Barnes E, Petrone A, Barr T, Theeke L. A systematic review of loneliness and common chronic physical conditions in adults. Open Psychol J 2015; 8: 113-32.

[9] Campbell M. The use of telephone help-lines by lonely children and adolescents. Open Psychol J 2015; 8: 133-7.

[10] Rosenstreich E, Margalit M. Loneliness, mindfulness, and academic achievements: a moderation effect among first-year college students. Open Psychol J 2015; 8: 138-45.

(C) Ami Rokach; Licensee Bentham Open.

This is an open access article licensed under the terms of the Creative Commons Attribution Non-Commercial License (http://creativecommons.org/licenses/ by-nc/3.0/) which permits unrestricted, non-commercial use, distribution and reproduction in any medium, provided the work is properly cited. 